\title{
THE MECHANISM OF DEATH FROM QUINIDINE AND A METHOD OF RESUSCITATION; AN EXPERIMENTAL STUDY
}

\author{
By BURGESS GORDON, MARCEL MATTON ${ }^{1}$ AND S. A. LEVINE
}

(From the Medical Clinic of the Peter Bent Brigham Hospital and the Department of Medicine of the Harvard Medical School)

(Received for publication April 7, 1925)

\section{INTRODUCTION}

Fatalities have occurred not infrequently during the clinical administration of quinidine in patients suffering from heart disease. At first particular emphasis was attached to the rôle that embolic phenomena played in producing unexpected deaths $(1,2,3)$. Later it was found that during quinidine administration occasionally there developed increased irritability of the ventricles, as evidenced by the appearance of extraventricular systoles and ventricular tachycardia $(4,5)$. It was thought, therefore, that ventricular fibrillation, the most extreme type of ventricular irritability, might explain some sudden deaths following quinidine.

It soon became apparent that neither of these explanations could account for a further group of such fatalities. This latter feature was particularly impressed upon us in our clinical experience for, in the three fatalities that occurred in the wards of the Peter Bent Brigham Hospital following quinidine therapy, post-mortem examination failed to show any evidence of emboli, and in one of the cases death was not instantaneous. In this patient, a peculiar toxic state resulted, somewhat resembling shock, or at least giving the appearance of unusual respiratory distress for some hours before the fatal termination. We found that similar cases have been reported by others $(6,7)$, in which this peculiar toxic state occurred. Von Frey (8) in 1918 reported two patients who received 0.2 gram of quinidine five

\footnotetext{
${ }^{1}$ Research Fellow of the Commission for Relief in Belgium Educational Foundation:
} 
times a day. Three hours after the last dose he found that they" presented a picture of cerebral paralysis. The patients had a sense of dizziness and increasing warmth, after which they suddenly fainted. They grew pale and the respirations became slower and stopped. After a short time the pulse could not be felt. The patients recovered after artificial respiration was given, and the recovery was accompanied by a stronger heart action. He gave epinephrin solution and thought it had a favorable effect. He also used caffein and camphor, but without result. As one patient was recovering from the fainting attack following the period of apnea, he noticed some evidence of motor excitability, with hallucinations and grimaces of the face. In the second case, while the patient remained unconscious for several hours, on three occasions her condition became worse, this being characterized at first by a standstill of the respiration. Von Frey concluded in these cases that there was no evidence of a paralyzing effect of quinidine on the heart muscle, but rather that the results pointed to a central action, the effect being at first on the respiratory center. Cordier (9) in 1923 reported his observations on a case of quinidine poisoning. This patient, a woman of fifty, suffering from heart disease, was receiving by mouth 0.2 gram of powdered quinidine a day. She became indisposed and he noticed that she was breathing with difficulty, developed apnea and finally fainted. This occurred three times in the same night. He observed no changes in the pulse except a slight acceleration and weakness at the end of the crisis. Long periods of apnea were noted by Neuhof (10), and Reid (11) found evidences of respiratory failure following the administration of quinidine in human cases. Wiechman (12) observed that in cases of quinidine poisoning there was clinical evidence of damage to the respiratory center. This; however, was accompanied by marked changes in the circulation. Vasquez and Leconte (13) and Korns (14) did not believe that quinidine ever really caused death. Exitus, they thought, was due to some underlying heart condition. This brief review indicates that there is considerable confusion as to whether the heart or the respiratory system is the one that becomes intoxicated primarily. It was with the purpose of studying the mechanism of death and thereby obtaining information as to whether we had any means of preventing such catastrophes that the following investigation was undertaken. 


\section{EXPERIMENTAL TECHNIQUE}

Sixty adult male cats were used in these experiments. They were etherized, placed on an animal board, and held in the dorsal position. The femoral artery and vein were exposed and 0.1 gram of heparin (15) dissolved in $2 \mathrm{cc}$. of physiological salt solution was injected intravenously. A cannula was inserted in the left femoral artery and was connected with a manometer apparatus by means of a short piece of rubber tubing. The tubing contained $30 \mathrm{cc}$. of a 3 per cent acacia solution and $10 \mathrm{mgm}$. of heparin under slight pressure. Stopcocks which separated the manometer and the cannula from the blood stream of the animal were then opened and a graphic record of the arterial pressure was traced on a smoked drum. A pneumograph was placed around the animal's chest and connected with a tambour apparatus; a marking signal and timing device were also in contact with the kymograph. When intratracheal artificial respiration was to be given, the trachea was exposed and opened, by means of a V-shaped incision. A T-shaped cannula was then inserted into the trachea and connected with a compressed air apparatus. The amount of air was regulated by opening and closing one end of the cannula at a rate to correspond with normal breathing. In taking the electrocardiograms, the hair on the two front legs and the left hind leg was clipped and contacts were made by means of gauze strips soaked in salt solution. They were connected with the apparatus in the usual manner. A 5 per cent solution of quinidine bisulphate (manufactured by Howards and Sons, Ilford, England) was freshly made for each experiment. The various doses of quinidine were injected with a tuberculin syringe into the right femoral vein. For the Roentgenograms, the same animal board and technique as employed in a previous study (16) were used, except that in this experiment the current was of 30 milliamperes and the exposure for 2 seconds. It consisted of making rapid exposures of the heart without disturbing the position of the animal. In determining changes in heart size, tracings on smooth white paper were made from the heart shadow; silhouettes were then cut out and weighed in milligrams.

\section{LETHAL EXPERIMENTS}

A series of lethal experiments was carried on in animals of known weight. They indicated, first of all, that there was some relation between the weight of the animal and the size of the dose. We tried to determine whether there was any relation between the speed of administration and the minimal lethal dose, as Cohn and Levy (17) have pointed out that the "greater the fractionation of the dosage, the greater was the amount of drug necessary to cause death." We, likewise, found that the animal could tolerate a much greater amount of the drug when it was divided over a period of time extending from 
half an hour to two or more hours than if larger individual doses were given more rapidly. As a result of numerous experiments it was found that 25 to $30 \mathrm{mgm}$. per kilogram were fatal when given in one dose. The total minimal lethal dose, however, if $15 \mathrm{mgm}$. were given every six minutes, was $45 \mathrm{mgm}$. per kilogram. It was possible by giving still smaller divided doses over a period of two hours to administer $100 \mathrm{mgm}$. per kilogram before the lethal effect was obtained. This total dose was four times as great as the minimal lethal amount when one single dose was given. Although the above figures hold in a general way, there were appreciable variations in some experiments. A striking thing about these animals was that practically no ether was required after the first injection, as the quinidine seemed to be sufficient to produce a state of narcosis.

\section{NON-LETHAL EXPERIMENTS}

In this series of experiments a small single dose was given in order to determine the margin of safety for administration. A single dose of $20 \mathrm{mgm}$. per kilogram caused no appreciable change in the respiration except occasionally a slight slowing. On the other hand, when a dose of $25 \mathrm{mgm}$. per kilogram was given, which was in the vicinity of the lethal dose, there was frequently a brief cessation of the respiration, followed by a slow rate and a gradual return to normal. In about one half of the instances the dose was fatal. In other experiments a total of $76 \mathrm{mgm}$. per kilogram administered in divided doses over a period of two hours was not fatal, but caused some slowing of the respiration and a moderate narcosis.

These results stand out in marked contrast to those obtained when digitalis is given, for here the speed of administration does not alter the minimal lethal dose (18). Some of the animals were returned to the cages, where they completely recovered. The others were used for different purposes. In several it was found that, following injections of quinidine, apparent recovery of the animal took place within a few hours and complete recovery in twenty-four hours, in the sense that similar repeated injections could be given without any evidence of an accumulative action of the previous administration. This corresponds quite well to the observations made by Lewis (19) who found that quinidine was completely excreted in approximately one day. 
As Cohn and Levy (17) and other workers have observed, there was a constant sudden drop of the blood pressure following the first injection of quinidine. This was not always related to the size of the dose. We found that the degree of this fall varied between forty and eighty millimeters of mercury or more. There occurred quickly a gradual although incomplete return to the normal level. There was a tendency of the blood pressure to remain low for a longer time when the dose was large, the return also being less complete. The average time between the first drop in the pressure and the return to the next highest level was from five to ten minutes. The drops following successive injections grew less in extent than those following the previous ones, and the recovery of the pressure was also less marked, so that in studying a long chart there was a stairlike effect on the pressure curve, which remained for some time at a level of about 30 to $40 \mathrm{mgm}$. of mercury if no further injections were given (fig. 1).

The question arose as to whether the fall in the pressure was due to an action on the heart muscle itself or whether it was due to a peripheral vascular dilatation. With this in mind, experiments were performed in which the abdominal aorta was compressed. Referring to figure 2 it will be seen that after obtaining a record of the normal pressure, compression of the abdominal aorta elevated the carotid arterial pressure $75 \mathrm{~mm}$. of mercury above the normal level. While the aortic pressure was being maintained an intravenous injection of quinidine produced a fall of about $40 \mathrm{~mm}$., which level was nevertheless $25 \mathrm{~mm}$. higher than the normal readings before compression of the aorta. When the abdominal aorta was released there was an immediate fall in pressure to a level that would have corresponded to that obtained from the quinidine if no aortic compression had been employed. Several minutes later when the blood pressure had returned to its highest level, the aorta was again compressed with a similar rise of about $80 \mathrm{~mm}$., bringing the reading to $155 \mathrm{~mm}$., nearly as high as the level reached after the first injection. From this point a second injection of quinidine again produced a fall of about $30 \mathrm{~mm}$., and when the aorta was released a drop occurred which corresponded to about 

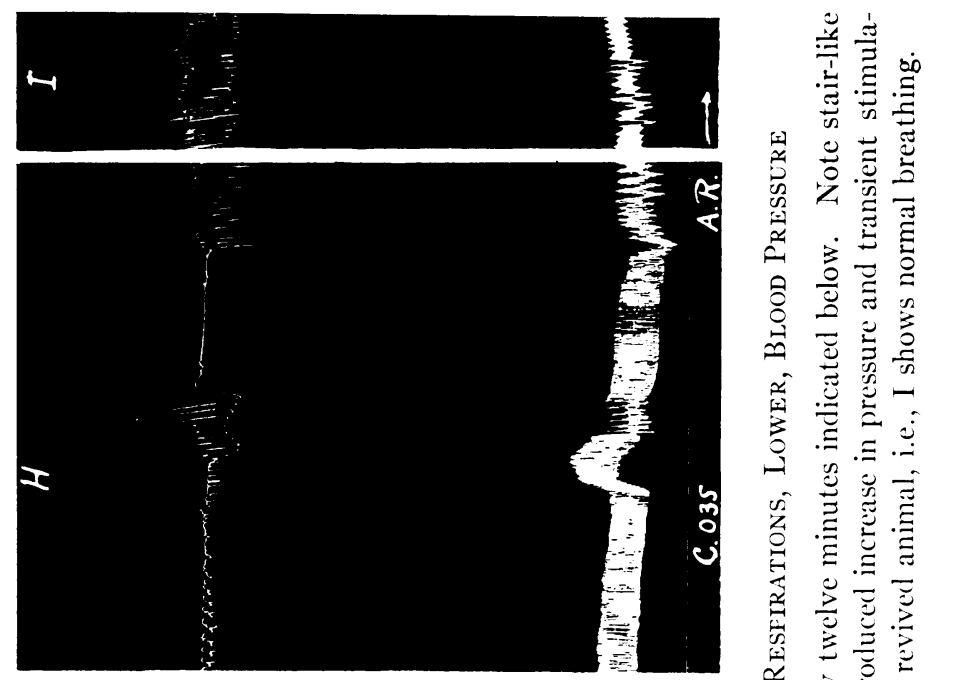

苛苛

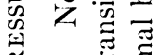

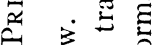

คิ $)$

๓.

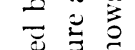

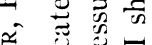

舲

○.

क

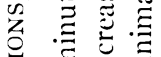

$\Xi \cong$

在

嵌芯冚苛

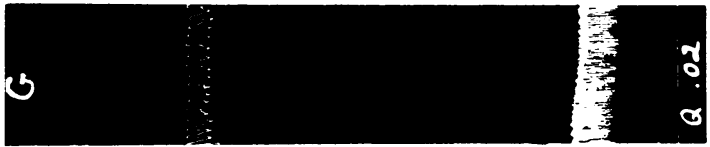

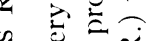

o

की

药

公

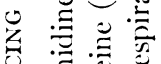

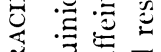

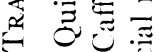

渮

思苛焉

के

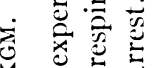

प

+.

$\mathrm{N}$

9
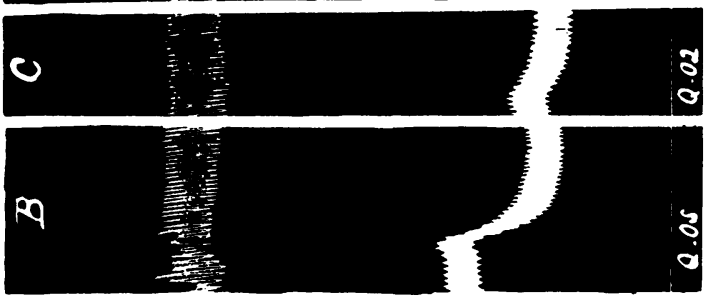

)

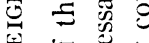

$=0$

- 舟

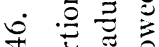

+

¿ $\Xi$

$\therefore \sim$

$\dot{0} 0$ 密

西跑

.气̊ำ.

$x^{\circ}$

ชู

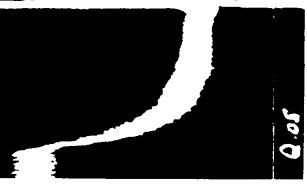

诘. 
the previous low level. This experiment is not critical in differentiating the effect of quinidine on the vessels from the direct action on the heart muscle. But the fact that quinidine produced only a partial fall of pressure while the abdominal aorta was completely compressed indicates that the action of the drug, at least in a great measure, is on the abdominal or peripheral vessels. Definite evidence for an additional effect on the heart muscle was obtained from a different angle

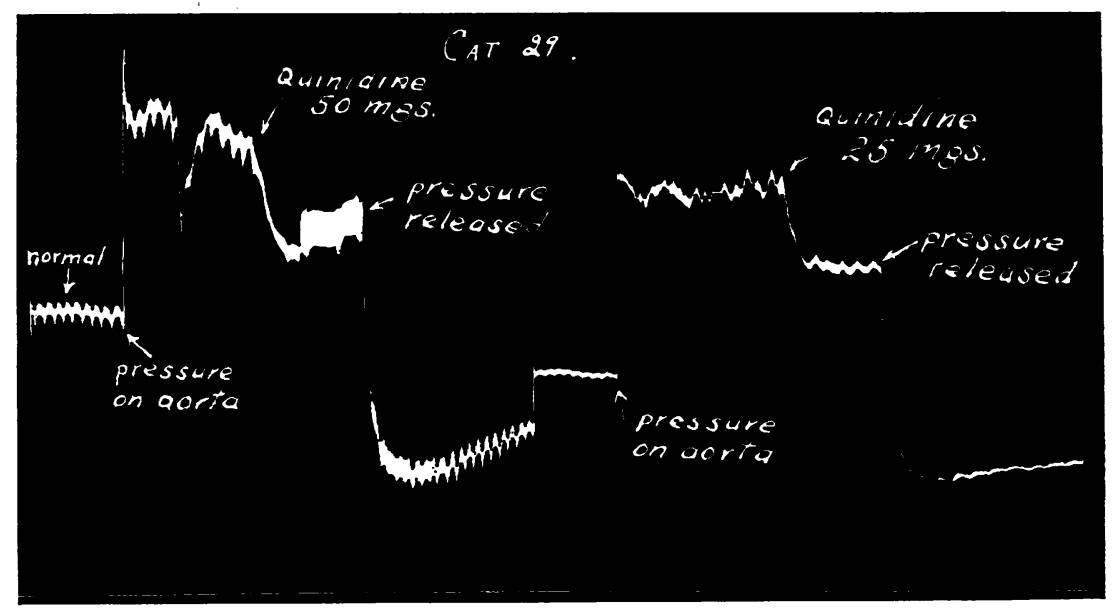

Fig. 2. Cat 29. Weight, 3.9 KGm. Blood Pressure Record.

Note increase in pressure following compression of the abdominal aorta and partial fall as a result of quinidine, with further fall after release of aortic compression.

in that the changes seen in the electrocardiograms (see below) were of a type that is found only when the heart muscle is undergoing serious damage.

\section{OBSERVATIONS ON THE RESPIRATION}

Von Frey and Haegeman (20), working on rabbits, observed that quinidine had at first a paralyzing effect on the heart muscle and only later affected the respirations. On the other hand, in this investigation we found that a single dose of $30 \mathrm{mgm}$. per kilogram or more caused the respiration to become irregular, then it grew slow and 
shallow and soon ceased. When a smaller dose was given, the respirations occasionally ceased for a few seconds and then continued, at first slowly and later in a normal manner. A dose of about 15 to $20 \mathrm{mgm}$. per kilogram merely caused a slight but noticeable slowing of the respiratory rate, lasting for two or three minutes and then gradually the breathing resumed a normal rhythm.

In giving repeated injections every twelve minutes, the total amount of which constituted a lethal dose, no striking change occurred until the fifth or sixth injection. Then the rate of respiration became slow and shallow, which lasted for five or six minutes, so that just before the next injection the breathing was quite normal. The same phenomenon took place after the next injection, but in a more serious way, and there was a more gradual return to normal. Finally, when the lethal dose was reached, the animal stopped breathing, although the heart continued to beat for three or four minutes longer. This is in accordance with the findings of Korns (14) who briefly mentioned that if artificial respiration was performed on guinea pigs they could withstand larger doses of quinidine. However, he failed to appreciate the importance of this observation, for he added that his dogs died of ventricular fibrillation, although respiration ceased only a few minutes before death. In a study to determine the effect of ouabaine (18) it was found that when ventricular fibrillation was the cause of death, the respirations continued for an appreciable length of time after the ventricular fibrillation had begun and mechanical contraction had ceased. This was a constant occurrence in the death from ouabaine. It is altogether likely that in Korn's observations respiratory paralysis preceded and was in a great measure responsible for the death of the animals and the ventricular fibrillation was the sequel rather than the cause of death as it always followed cessation of breathing. It was practically an invariable experience in our experiments to find that the heart continued to beat after the respirations had ceased (fig. 3).

THE GENERAL APPEARANCE OF THE ANIMAL

Mention has been made of the peculiar narcotic state of the animal following the first non-lethal injections before the appearance of marked symptoms. After a considerable amount of quinidine had 

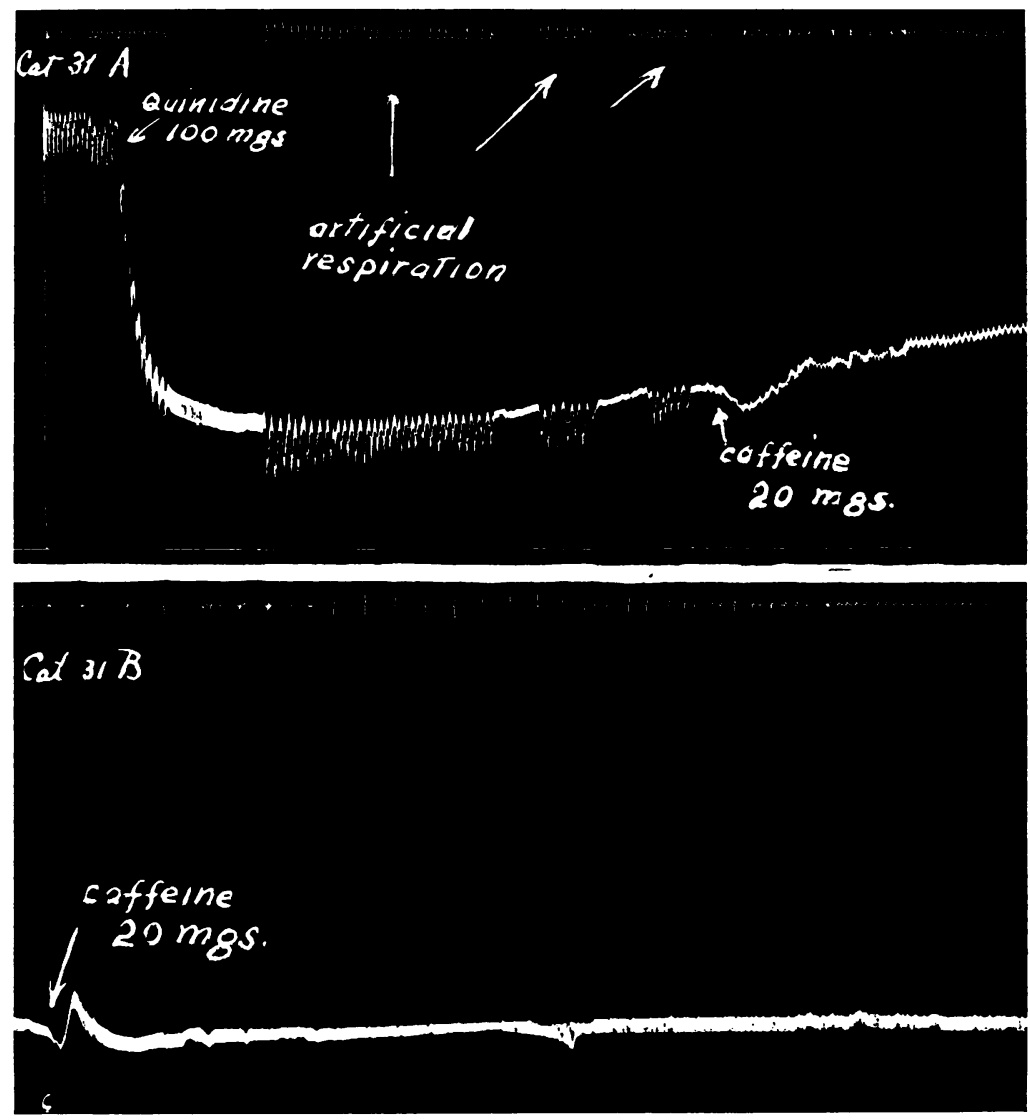

Fig. 3A. Cat 31. Weight, 5 kgm. Upper Tracing Indicates Respirations, Lower Blood Pressure.

Note sudden marked drop in pressure following quinidine with cessation of respiration. Three periods of artificial respiration failed to institute spontaneous breathing. After caffeine was given normal breathing returned.

Fig. 3B. Between A and B Sufficient Quininine Was Given to Produce Cessation of Breathing

Note that caffeine alone produced return of normal respiration although blood pressure remained low. 
been given, it was not uncommon for the cat to develop short periods of convulsions. At this stage frequently there was also a livid appearance of the lips, and from time to time the cat tossed his head from side to side and threw his legs about limply. In some cats there was a relaxation of the sphincters. The asthenic appearance of the animals closely resembled the appearance of intoxication that one of our patients who died following the oral administration of small doses of quinidine presented during the last few hours of life.

\section{MEANS OF RESUSCITATING THE ANIMAL}

At the beginning of this study it was our impression that the cats were dying a cardiac or circulatory death. In some experiments heart drugs such as ouabaine, strophanthin, and digitalis were given intravenously when symptoms of catastrophe appeared. We also used the drugs before starting the injection of quinidine with an idea of preventing the deleterious effect on the heart and the circulation. The harmful effects of qunidine were neither prevented nor removed by the use of these drugs. Von Frey and Haegeman (20) made the same observations. Suspecting that the failure might be due to vasodilitation, causing a low blood pressure so that the vital centers failed to receive a sufficient blood supply, we placed the animal head down, but observed no changes in the respirations (fig. 4). It quickly occurred to us that the respiratory mechanism was affected, at least in a measure, independently of the circulation. Although the lower state of blood pressure could account for a part of the respiratory distress, it seemed unlikely that it played an important rôle, for it has been observed frequently in these experiments that cats were breathing normally with extremely low blood pressures (fig. 1, Section E). As it was felt that caffein has a stimulating effect on the respiration (21), we thought that it might be of value if the phenomenon were respiratory collapse. Thus in a group of animals we gave a moderately large dose of quinidine, a dose sufficient to produce respiratory embarrassment. At the point when the cat was breathing poorly, and just about the time a standstill in the respiration seemed to be imminent, an injection of caffein sodium benzoate was given (about $5 \mathrm{mgm}$. per kilogram). In most instances the normal breathing returned (fig. 4). Other cats received sufficiently large doses 

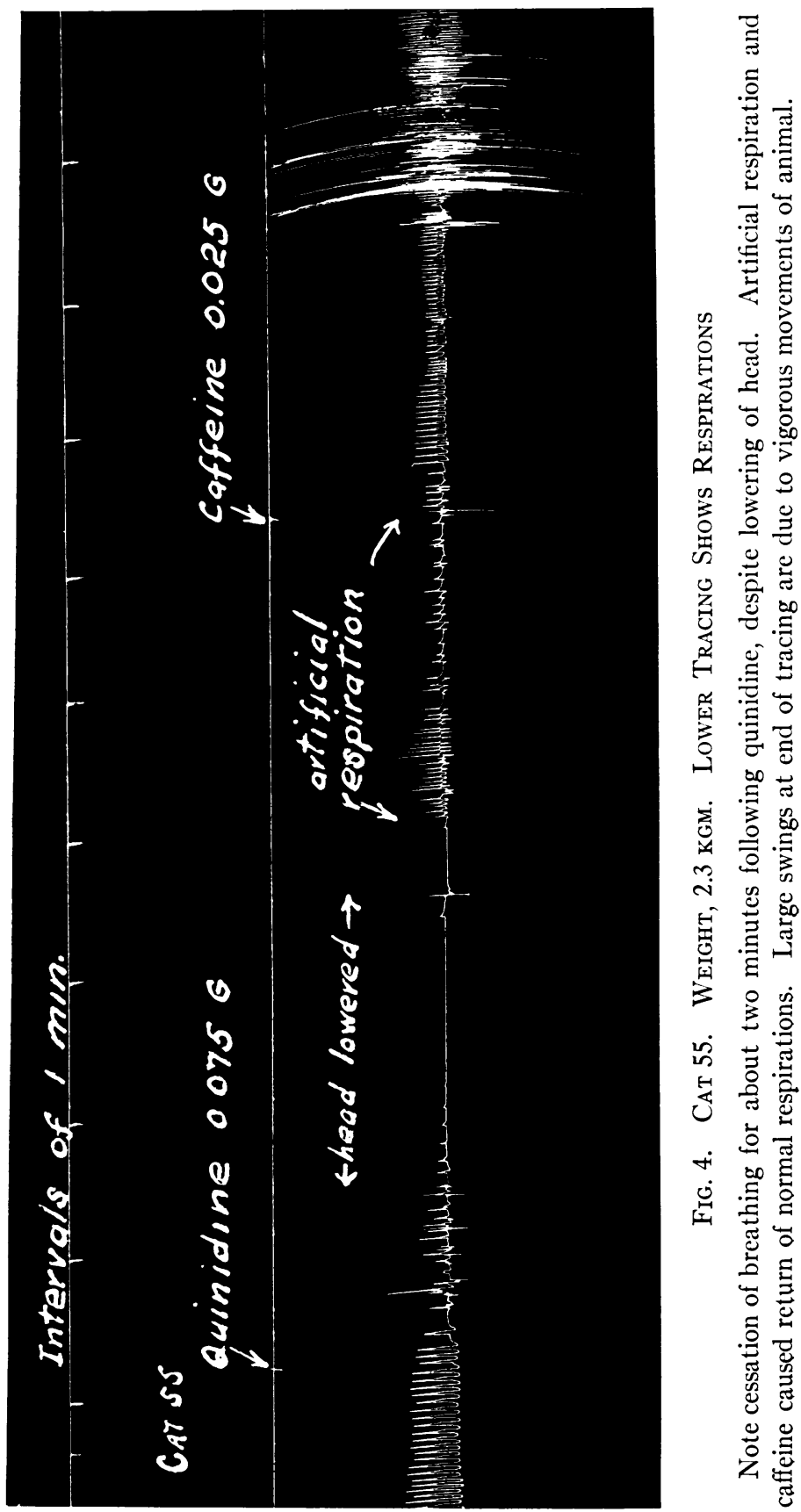
of quinidine to produce complete respiratory failure. One minute after breathing had stopped, an intravenous injection of caffein was made. In about one half of this series, after a few slow and deep breaths, the normal breathing returned (fig. 4).

To determine whether it was possible to prevent untoward symptoms following the administration of dangerous doses of quinidine, the following experiment was done. The animal was given as a control $25 \mathrm{mgm}$. of quinidine per kilogram. The respiration was very definitely affected. The rate was slow and the breathing shallow, but the animal recovered. The next day caffein was given first and followed by the same dose of quinidine, without noticeable change in the respiration. One day later, the same animal was given 30 $\mathrm{mgm}$. of quinidine and the respiration stopped; caffein $(5 \mathrm{mgm}$. per kilogram) was given intravenously. The respiratory rate returned to normal and the animal recovered. These experiments were repeated on the same cat and similar results were obtained. The above experiments indicate a definite beneficial effect of caffein on the untoward depression of the respiratory mechanism following quinidine.

The possibility of saving all cats, either from a large single lethal dose of quinidine or from repeated small doses of such amounts as were usually lethal, was then considered. When the cats stopped breathing, artificial respiration by means of chest massage was given. This procedure failed completely if vigorous or rapid manipulations were used in carrying out the massage. On the contrary, it was quite dependable in cats not hopelessly intoxicated by quinidine when the respiratory movements were made in a slow careful manner to correspond to the normal rate of the respiration. It was felt, however, that with more complete ventilation of the lungs, it might be possible to save the animals more readily. Therefore, intratracheal artificial respiration as described above was undertaken. This method seemed to be far more efficient. Cats given fatal amounts of quinidine either in a single massive dose or in small repeated doses which were sufficient to produce cessation of the respiration for as long as two minutes, were saved by this procedure. Some cats in which automatic breathing had stopped were given artificial respiration for from fifteen to twenty minutes before normal 
breathing returned. The heart action during this period of respiratory failure was satisfactory, the blood pressure ranging around $40 \mathrm{~mm}$. One cat which received a very large dose, i.e., 50 per cent larger than the lethal dose, stopped breathing for two minutes. The animal was inverted with no effect. Artificial respiration by the intratracheal method was then instituted and was stopped at intervals, about every minute, to determine if the animal were breathing spontaneously. After nine minutes normal respiration returned. The next day the animal was in good condition and the same dose was repeated. When respiration ceased the cat was again inverted, without any beneficial result. Then artificial respiration was started, but at the same time an intravenous injection of $25 \mathrm{mgm}$. of caffeine sodium benzoate was given. At the end of one minute artificial respiration was stopped, and at that time the cat was breathing normally (fig. 4). Whereas on the previous day it required nine minutes of artificial respiration before the normal breathing returned, in this experiment the cat was breathing after one minute. It seems, therefore, that the combined action of the two procedures, i.e., artificial respiration and caffeine, restored the animal more quickly and more efficiently than artificial respiration alone. In numerous experiments similar recovery of the animals after lethal injections of quinidine occurred.

\section{OBSERVATIONS ON THE HEART}

Santesson (22) as early as in 1893 concluded that the action of quinidine was essentially a muscle poisoning. Waddell and Cohen (23) in an experimental study on the amphibian heart thought that the quinidine produced its effect through an action on the musculature of the heart and of the circulatory system, and they considered it to be a physiological depressant.

Throughout our experiments, numerous electrocardiograms were taken. In general it was found that with small doses of quinidine transient changes in the ventricular complexes occurred. The duration of the Q-R-S complex was prolonged and the amplitude of the $\mathrm{R}$ and $\mathrm{S}$ waves was also increased. Frequently there was a slight delay in the P-R interval and even heart block as were noted by Korns (14), and Lewis et. al. (24). These changes disappeared before the next injection. The general type of curves is similar to those 


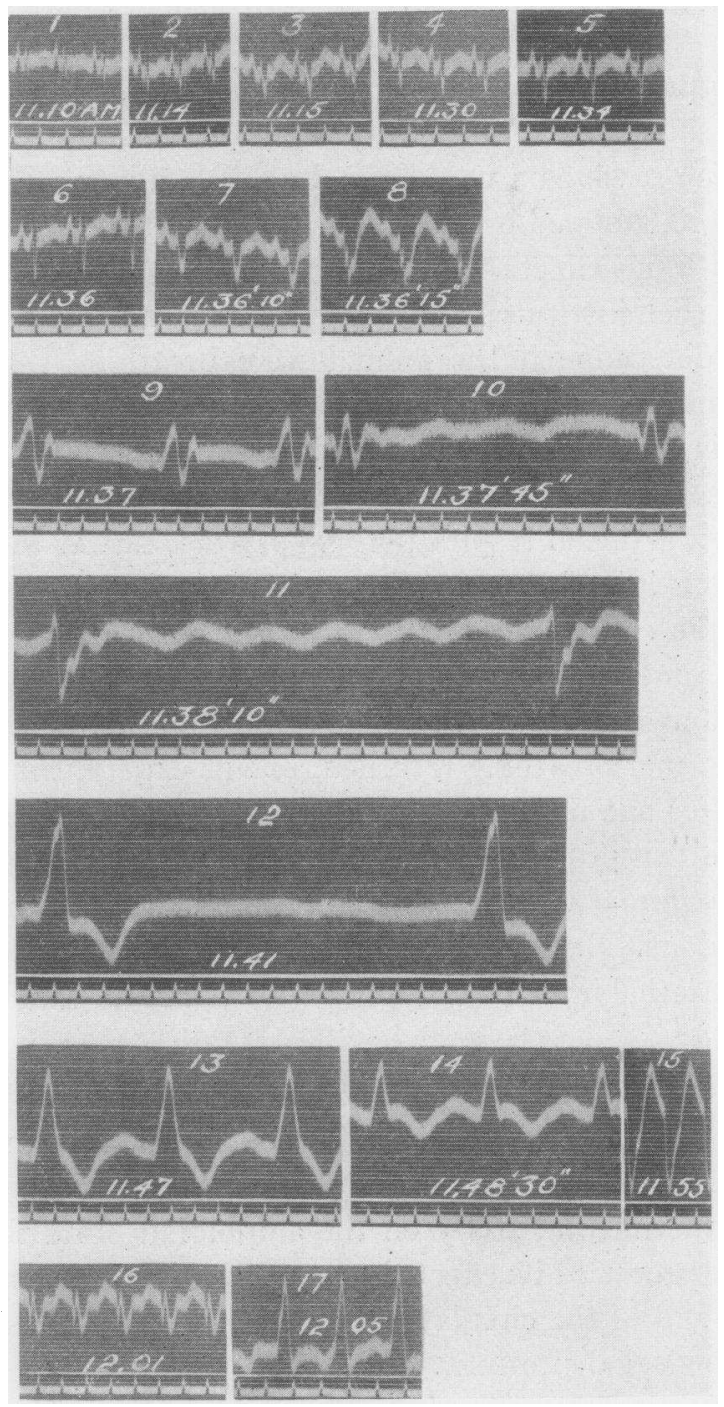

Fig. 5. Cat 41. Weight, 3.4 kgm. All Electrocardiograms are lead 2.

Timer below measure $\frac{1}{5}$ second. The time the various tracings were taken is indicated below each curve. No. 1 is normal control. Quinidine $25 \mathrm{mgm}$. given at 11.13 a.m. Quinidine $25 \mathrm{mgm}$. given at $11.29 ; 15 \mathrm{mgm}$. at $11.33 ; 25 \mathrm{mgm}$. at 11.35. Respirations stopped at 11.37. At 11.38 caffeine sodium benzoate 20 mgm. given. Artificial respiration from 11.40 to 11.50 caffeine $10 \mathrm{mgm}$. at 11.55 . Note slight slowing and changes in the complexes with early doses of quinidine and more marked changes with later doses. Striking recovery followed artificial respiration and caffeine. 
seen in the upper two sections of figure 5. The electrocardiographic changes became progressively more marked with repeated injections, with a gradually diminishing degree of recovery. The heart rate in most instances was slow and death occurred without fibrillation of the ventricle in the great majority of instances. The final tracings were apt to show bizarre ventricular curves. In those instances where the respirations had ceased entirely and it seemed that the animal would certainly die, electrocardiograms could still be obtained, although they indicated a most grave state of intoxication. Despite the dangerous outlook, artificial respiration was successful, both in reviving the respiratory mechanism and in allowing the heart to be restored so that in about two hours electrocardiograms were essentially normal. An example of recovery after a lethal dose of quinidine was given is shown in figure 5 . When such extraordinary curves were obtained and means of resuscitation were not employed, the animal invariably died, but here satisfactory heart as well as respiratory recovery occurred by means of artificial respiration.

By means of roentgenographic examination it was found that within a few seconds following the injection of $22 \mathrm{mgm}$. of quinidine per kilogram there began a diminution in the size of the heart. There was further contraction during a period of seventy seconds and thereafter the heart rapidly dilated to a size greater than the normal control, with eventual return to normal (fig. 6). With the subsequent injections of smaller doses of quinidine there was a diminution in the heart size which was not followed by the period of dilation before the gradual return to normal that occurred in the former case. In figure 6 the first changes in the size of the heart as indicated by a decrease in the weight of the silhouettes, although small, are in fact significant. It was generally considered that changes under 10 per cent were within the limit of error (25) and the fall from 0.061 to 0.056 might be within this margin. But the decrease in the heart size continued, as was indicated by the figure 0.051 which could not be considered an error in technique. Furthermore, similar alterations were observed in the same animal, which makes it more certain that a true contraction occurred directly after each injection. There can be no doubt that a subsequent dilatation occurred, for the change from 0.051 to 0.077 is an increase of 50 per cent. Figure 7 likewise shows these changes in the actual roentgenograms. 

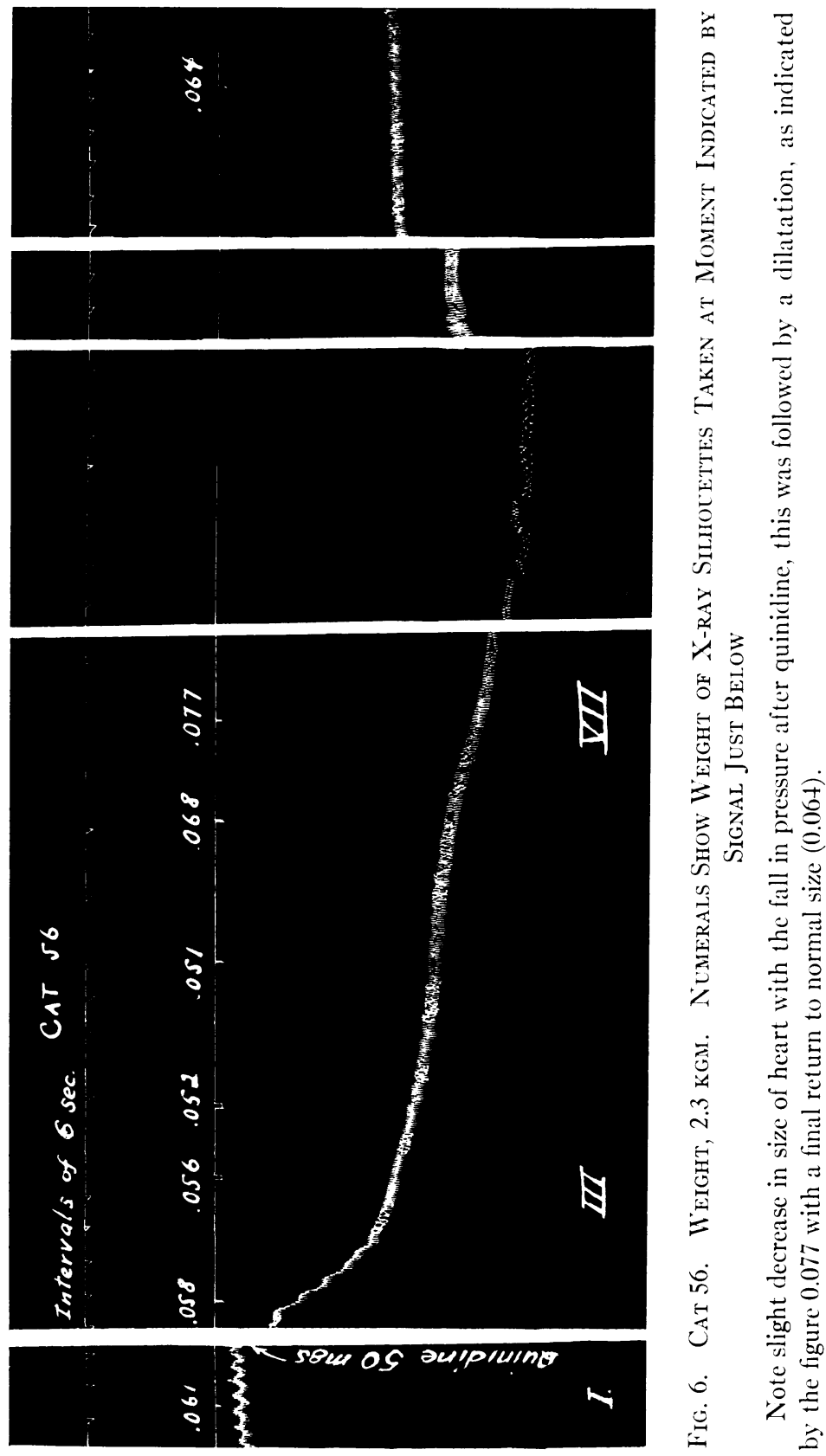


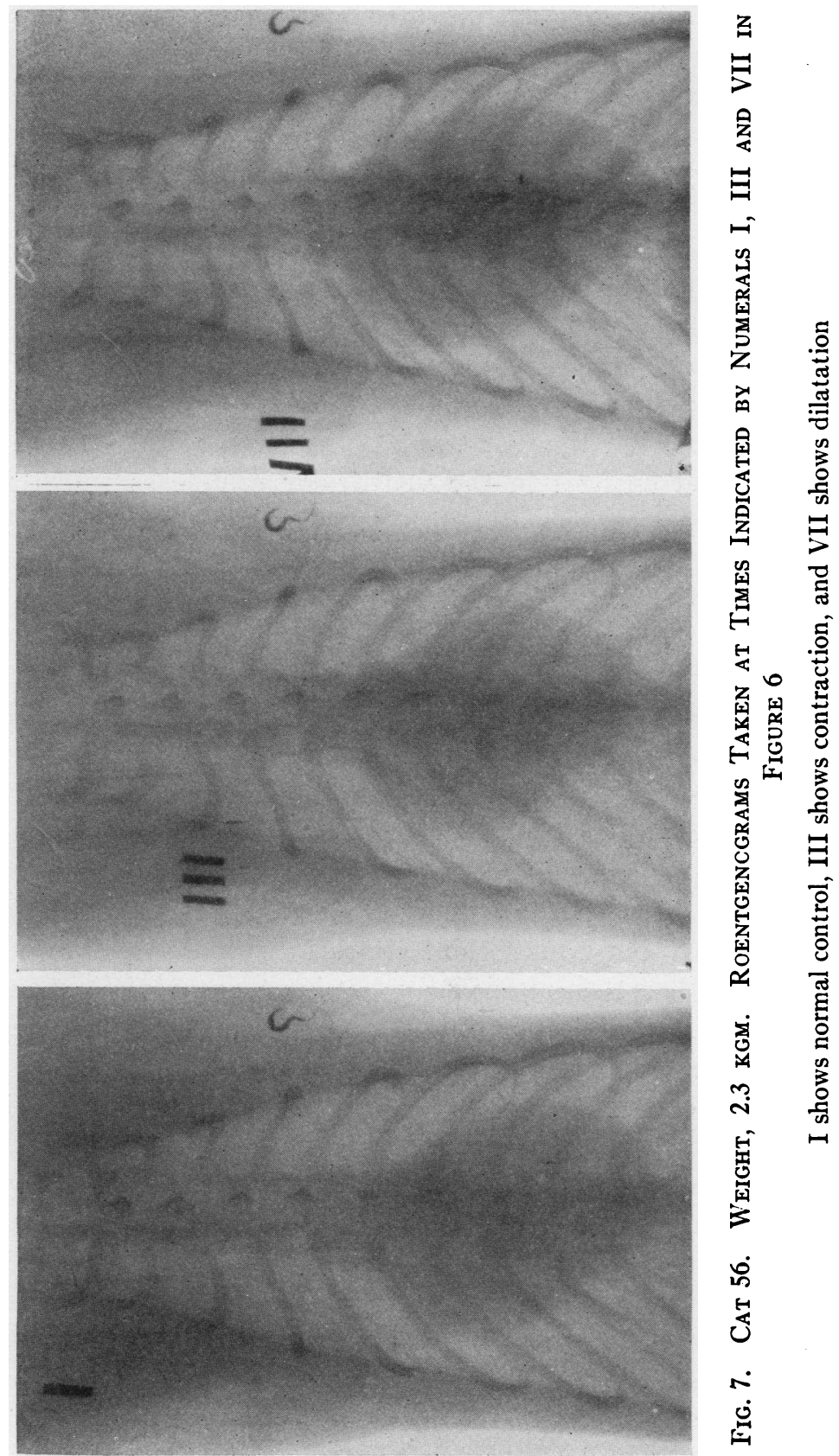


These observations in general are in accord with those of Jackson, Friedlander and Lawrence (26), despite the fact that in their experiments the chest was opened and considerable manipulation of the heart was necessary, whereas here, intact animals were employed. It seems most likely that the initial contraction was related to the sudden fall in pressure and was independent of any local action of the drug on the heart. It was recently shown (16) that with the fall in pressure that accompanied amyl nitrite administration and bleeding there was a similar contraction in the heart. The dilatation that occurred following the initial contraction after quinidine injection probably resulted from direct action of the drug on the heart muscle, as it was about that time that repeated electrocardiograms on the animals showed changes in the ventricular complexes which were indicative of intoxication of the muscle. Six minutes after quinidine administration, the heart size returned to normal, although the blood pressure only partially recovered. This would correspond with the recovery of the heart as seen in electrocardiographic studies. The above changes are also in accord with the observation of Waddell and Cohen (23) who found evidence of decreased elasticity of the heart muscle when it was perfused with quindine. The changes in the heart size noted above and indicated in figure 7 were produced by a two-fold mechanism; the peripheral action of quinidine producing a fall in blood pressure accounted for the contraction of the heart, and the direct action of the drug on the heart muscle in certain concentrations produced a dilatation. Both of these factors influenced the size of the heart simultaneously, but in an antagonistic manner, the resulting size was at any minute dependent on the relative degree to which one or the other was most effective.

The above experiments conciliate some of the conflicting views expressed by previous observers. There is positive evidence of heart muscle intoxication following quinidine. However, the respiratory paralysis cannot be explained by any other mechanism than a specific effect on the respirations and not as an indirect result of low blood pressure. Experience in the clinic with one patient who died following quinidine therapy and who showed respiratory embarrassment some hours before death makes it seem likely that means of resuscitation which proved so successful in these experiments might be applicable to human cases. 
CONCLUSIONS

1. As a result of experiments on cats the minimal lethal dose of quinidine bisulphate was found to be dependent upon the speed of administration. Whereas $25 \mathrm{mgm}$. per kilogram were usually fatal when given in a single dose, on the other hand, when smaller doses were given at intervals of from six to twelve or twenty-four minutes, the total minimal lethal dose correspondingly increased to about 0.1 gram per kilogram.

2. Immediately following injections of non-lethal doses of quinidine there was a striking fall in blood pressure. This began a few seconds after the administration was started.

3. The effect on the respiration was directly proportional to the size of the dose. In giving a small dose the breathing was essentially unaffected, whereas after a moderate dose, there was usually a temporary, very brief cessation of the respirations. With increasing sublethal doses there was a slowing of the rate and a decrease in the depth of the respirations. With lethal doses the breathing gradually failed and finally ceased. The heart always continued to beat after complete respiratory failure, for even as long as two minutes.

4. The appearance of the animals under quinidine intoxication was not unlike that manifested by a fatal case in the clinic.

5. It was found that when animals were given lethal doses and the respirations had ceased for a period of one to two minutes, they could be revived satisfactorily by artificial respiration combined with the use of caffeine sodium benzoate. The caffeine alone was frequently sufficient, although artificial respiration alone was much more effective. When the two procedures were combined recovery took place more rapidly.

6. There were changes in the electrocardiograms of varying degree, depending on the size of the dose. With small doses the changes were slight and transient. With larger ones the curves indicated a grave intoxication of the heart muscle. Fibrillation of the ventricle was very rarely observed.

7. Roentgenograms taken at freqent intervals during the fall of pressure after an injection of a moderately large dose of quinidine showed at first a slight contraction of the heart followed by a dilata- 
tion. With small doses a contraction but no dilatation occurred. There was a marked dilatation as a terminal event.

8. It is suggested that the method of resuscitation employed in reviving the animals in these experiments may be applicable in the clinic in the treatment of quinidine intoxications.

We wish to take this opportunity of expressing our indebtedness to Miss Bertha I. Barker for her devoted assistance in these experiments.

\section{BIBLIOGRAPHY}

1. Mackenzie, J.: Brit. Med. Jour., 1921, ii, 514. The Manner in which Quinidine Sulphate acts in Auricular Fibrillation.

2. Viko, L. E., Marvin, H. M., and White, P.: Arch. Int. Med., 1923, xxxi, 345. A Clinical Report on the use of Quinidine Sulphate.

3. Burwell, C. S., and Dieuaide, F. R.: Arch. Int. Med., 1923, xxxi, 518. Clinical Experience with Quinidine.

4. Levy, R. L.: Jour. Amer. Med. Ass., 1922, lxxix, 1188. Clinical Studies with Quinidine. The Clinical Toxicology of Quinidine.

5. Kerr, W. J., and Bender, W. L.: Heart, 1922, ix, 269.

6. Oppenheimer, B. S., and Main, H.: Jour. Amer. Med. Ass., 1921, lxxvii, 1800.

7. Clark-Kennedy, A. E.: Quart. Jour. Med., Oxford, 1921-1922, xv, 279. On the Therapeutic Value of Quinidine in the Treatment of Auricular Fibrillation.

8. Von Frey, W.: Berliner klin. Wochschr., 1918, lv, 849.

9. Cordier, V.: Lyon méd., 1923, cxxxi, 287. Des paralysies respiratoires, par l'emploi de la quinidine.

10. Neuhof, S.: Med. Jour. and Rec., 1924, cxx, 78. Quinidine Sulphate in Auricular Fibrillation. Its Administration in Private Practice.

11. Reid, W.: Jour. Amer. Med. Ass., 1922, lxxix, 1974. Respiratory Paralysis Following Quinidine Therapy.

12. Wiechman, E.: Klin. Wchnschrft., 1922, xxxiv, 1683. Untersuchungen über das Chinidin seine antagonsten und Synergisten.

13. Vaquez and Leconte: Bull. de l'Acad. d. Med., 1922, lxxxviii, 704. Action cardiaque de la quinidine.

14. Korns, H. M.: Arch. Int. Med., 1923, xxxi, 15. An Experimental Study of Quinidine sulphate.

15. Howell, W. H., and Holt, E.: Amer. Jour. Physiol., 1918, xlvii, 328.

16. Gordon, B., and Wells, G.: Arch. Int. Med., 1924, xxxiii, 733.

17. Cohn, A. E., and Levy, R. L.: Proc. Soc. Exp. Biol. and Med., 1920-21, xviii 283.

18. Levine, S. A.: Jour. Exp. Med., 1919, xxix, 485. The Action of Strophanthin on the Living Cat's Heart. 
19. Lewis, Thomas: Amer. Jour. Med. Sci., 1922, clxiii, 781.

20. Von Frey, W., and Haegeman E: Zeitsch. fur die ges. exper. Med., 1921, xxv, 290. Klinische experimentelle Daten uber Toxischechinidinewirkung.

21. Cushny, A. R.: Pharmacology and Therapeutics or the Action of Drugs. Philadelphia, 1918, 289.

22. Santesson: Arch. f. Exp. Pathol. u. Pharmak., 1893, xxxii, 312. Uber die Wirkung einer Chinaalkaloide auf des irregulare Froschherz und auf den Blutdruck des Kaninchen.

23. Waddell, J. A., and Cohen, M.: Jour. Lab. and Clin. Med., 1924, ix, 821.

24. Lewis, Th., Drury, A. N., Iliescu, C. C., and Wedd, A. M.: Heart, 1921, ix, 55.

25. Strong, G. F., and Gordon, B.: Arch. Int. Med., 1923, xxxii, 510, Studies on the Rabbit's Heart. Effect of Strophanthin on the Size of the Normal and of the Abnormal Heart.

26. Jackson, D. E., Friedlander, A., and Lawrence, J. V.: Jour. Lab. and Clin. Med., 1922, vii, 311. An Experimental Investigation of the Pharmacological Action of Quinidine. 